\title{
Equivalência e definição no Dicionário Bilíngue Português-Mundurukú da área do Magistério: contribuindo para a epistemologia terminológica e terminográfica
}

\section{Equivalence and definition in the Portuguese-Mundurukú Bilingual Teacher Qualification Dictionary: contributing for the terminological and terminographical epistemology}

\author{
Dioney Moreira Gomes* \\ Tânia Borges Ferreira**
}

Resumo: Este artigo apresenta algumas análises, reflexões e decisões tomadas durante a elaboração do Dicionário Terminológico Escolar Português-Mundurukú: Magistério, as quais implicaram determinadas escolhas terminológicas e terminográficas que podem contribuir para a epistemologia dessa área do conhecimento. Trataremos especificamente das equivalências e definições com base nos pressupostos teóricos da Teoria Comunicativa da Terminologia (TCT) e congêneres. Da metodologia envolvida na realização desta pesquisa, ressaltamos a relação com o método etnográfico e a pesquisa qualitativa nos usos de recursos e técnicas de coleta de dados em campo, na Terra Indígena Mundurukú (PA). Como resultados alcançados, mostraremos aqui o tratamento dispensado aos equivalentes

\footnotetext{
* Professor adjunto do Departamento de Linguística da Universidade de Brasília

${ }^{* *}$ Mestra em Linguística pela Universidade de Brasília
} 
Gomes, D. M.; FerReIRA, T. B. - Equivalência e definição no Dicionário Bilíngue PortuguêsMundurukú da área do Magistério: contribuindo para a epistemologia terminológica e terminográfica

e às definições na construção de um dicionário bilíngue terminológico escolar indígena.

Palavras-chave: Terminologia; Terminografia; equivalência; definição; Língua Mundurukú; Língua Portuguesa.

Abstract: This article presents analyses, reflections, and decisions taken during the elaboration of the Portuguese-Mundurukú School Dictionary: Teacher Qualification, which implicate into certain terminological and terminographic choices that may contribute to the epistemology of this knowledge area. We will deal specifically with the equivalencies and definitions based on theoretical de facto assumptions of the Terminology Communication Theory (TCT) and counterparts. On the methodology involved in the execution of this research, we highlight the relationship with the ethnographic method and the qualitative research in the use of field data gathering technical resources, in the Mundurukú Indigenous Land (PA). With the results achieved, we will show here the treatment displayed to the equivalents and definitions in the construction of a bilingual indigenous terminological school dictionary.

Keywords: Terminology; Terminography; equivalence; definition; Mundurukú; Portuguese.

\section{Introdução}

Este artigo tem o objetivo de apresentar algumas análises e reflexões realizadas durante a elaboração do Dicionário Terminológico Escolar Português-Mundurukú: Magistérioํㅡㄹ as quais implicaram determinadas escolhas terminológicas e terminográficas, que podem contribuir para a epistemologia dessa área do conhecimento linguístico. Trataremos especificamente das equivalências e definições.

\footnotetext{
1 Esse dicionário está sendo produzido, na UnB, pelo Prof. Dr. Dioney M. Gomes e suas orientandas: Tânia Borges Ferreira, Joice Oliveira Ventura e Thalita Chagas Siqueira.
} 
GOMES, D. M.; FeRreIRA, T. B. - Equivalência e definição no Dicionário Bilíngue PortuguêsMundurukú da área do Magistério: contribuindo para a epistemologia terminológica e terminográfica

Esta pesquisa segue os pressupostos teóricos da Teoria Comunicativa da Terminologia e congêneres (CABRÉ 1998, 1999, 2003 e 2005; GAUDIN 1993; FAulstich 1995, 1996; KRIEger 2001; Krieger \& FinatTo 2004, e outros). Por isso, concebe a linguagem de especialidade como integrante da língua natural e não como uma língua à parte. As unidades terminológicas também partilham dos elementos fonológicos, morfológicos, sintáticos e semânticos da língua natural na qual estão inseridas. Será por meio da pragmática e do discurso que essas unidades serão diferenciadas, realizando-se como unidades terminológicas, dependendo do valor adquirido no uso.

Da metodologia envolvida na realização desta pesquisa, ressaltamos a relação com o método etnográfico e a pesquisa qualitativa nos usos de recursos e técnicas de coleta de dados em campo, na Terra Indígena Mundurukú. Partindo desse embasamento, definimos a escolha dos participantes, a forma das entrevistas, o uso de fichas terminológicas e questionários, e destacamos as oficinas terminológicas/terminográficas como procedimento principal de coleta de dados. 0 uso dessas oficinas foi uma técnica de coleta de dados desenvolvida pelo grupo voltado aos estudos das terminologias em Mundurukú, cujo responsável é o professor doutor Dioney Moreira Gomes. As oficinas terminológicas/terminográficas consistem, em um primeiro momento, na reunião de um grupo de colaboradores diretamente envolvidos com a área do Magistério in loco, nas aldeias Mundurukú. Nessa etapa da coleta de dados, priorizam-se os professores indígenas, sobretudo os bilíngues, e os alunos do ensino médio integrado da área do Magistério. Com o grupo formado, apresenta-se o projeto de elaboração do dicionário terminológico escolar bilíngue, abrindo espaço para eventuais perguntas e dúvidas. Após a apresentação do projeto e do grupo, surgem as discussões sobre Terminologia e a importância de se preservar a língua Mundurukú, garantindo seu uso em um espaço especializado. Em seguida, inicia-se o processo de debate acerca de cada termo, lembrando que a proposta de 
Gomes, D. M.; FERREIRA, T. B. - Equivalência e definição no Dicionário Bilíngue PortuguêsMundurukú da área do Magistério: contribuindo para a epistemologia terminológica e terminográfica

verbete em Português já é levada para ser testada, criticada e/ou modificada durante as discussões geradas.

Como resultados alcançados, mostraremos aqui a interação entre a Terminologia/Terminografia e o tratamento dispensado aos equivalentes (seção 3) e às definições (seção 4). Antes, porém, na seção 2 apresentaremos brevemente o nosso projeto do dicionário que deu origem a este artigo.

\section{Projeto Dicionário Terminológico Escolar Bilíngue Português-Mundurukú: Magistério, Agroecologia e Enfermagem}

O povo indígena Mundurukú encontra-se nos estados do Amazonas (Rio Madeira) e Pará (Rio Tapajós). São hoje cerca de 10.000 pessoas, que mantêm contato com a sociedade dos não-índios há mais de 200 anos. Em sua maioria bilíngues, têm sentido, a cada dia, a necessidade de dominar a língua portuguesa em níveis avançados de Letramento. Hoje, já existem escolas de Ensino Fundamental funcionando em várias aldeias.

Em 2006-2007, iniciou-se um processo de implantação de escolas de Ensino Médio nas aldeias dos Mundurukú do Pará (cf. Ramos 2006), demanda dos próprios índios, que exigem condições de paridade com a sociedade circundante. Porém, não almejando um ensino comum, os índios propuseram que o Ensino Médio fosse integrado ao Ensino Profissionalizante, de modo a oferecer formação nas áreas de Agroecologia, Enfermagem e Magistério, áreas de vital importância para a sustentabilidade social, cultural e ambiental do povo Mundurukú. 
GOMES, D. M.; FeRREIRA, T. B. - Equivalência e definição no Dicionário Bilíngue PortuguêsMundurukú da área do Magistério: contribuindo para a epistemologia terminológica e terminográfica

Uma vez que essas áreas técnicas têm exigido leituras especializadas, propusemos a criação do dicionário de termos técnicos, assim como ocorreu com a nossa sociedade, em que surgiram dicionários de Linguística, Medicina, Sociologia, Direito, etc. Nasce assim o projeto “Dicionário Terminológico Bilíngue Português-Mundurukú: Magistério, Enfermagem e Agroecologia", o qual se encontra, em 2014, em sua fase final de elaboração.

Acreditamos que a construção de tal obra de natureza bilíngue e terminológica é crucial para a manutenção da língua Mundurukú. $O$ uso de equivalentes em Mundurukú para os termos identificados em Português é muito importante para o reconhecimento do valor linguístico e social daquela língua. Assim como é muito importante que as definições sejam claras, simples, objetivas e tecnicamente corretas. E é sobre os desafios que nos trazem equivalentes e definições que trataremos no presente artigo, trazendo a público resultados dos avanços alcançados na área do Magistério.

\section{Os equivalentes}

A equivalência é uma questão bastante complexa ao se trabalhar com Tradução, Lexicologia bilíngue ou Terminologia bilíngue. A primeira questão a ser abordada é que as línguas, consideradas repositórios culturais dos povos que se comunicam por meio delas, apresentam-se estruturalmente de forma diversa e carregam valores extralinguísticos. Tudo isso varia de uma língua para a outra, sendo bastante rara a existência de uma equivalência total entre palavras de duas línguas distintas. Por ter como foco a Terminologia, nos interessa encontrar equivalências conceituais, pois uma equivalência estrutural é bastante improvável, uma vez que trabalhamos com duas línguas estruturalmente bem distintas, o Português e o Mundurukú. 
GOMES, D. M.; FerReIRA, T. B. - Equivalência e definição no Dicionário Bilíngue PortuguêsMundurukú da área do Magistério: contribuindo para a epistemologia terminológica e terminográfica

Tratando da relação lema-equivalência, CARVALHO (2001) expõe cinco possibilidades existentes: a equivalência única, a relação divergente, a relação convergente, relação multivergente e a ausência de equivalência.

A equivalência única ocorre quando “(...) uma unidade lexical possui uma única equivalência que funciona como correspondência interlingual em termos semânticos e pragmáticos (...)" (CARVALHO 2001:114). Essa relação é um fenômeno raro. Nos nossos dados, encontramos poucas ocorrências deste tipo: quadro bararakap ${ }^{2}$

Essa relação de equivalência única só deve ter sido possível por se tratar de um objeto, da subárea Recursos Didáticos (R.D.) $)^{3}$, pois cremos que semanticamente é mais fácil encontrar equivalentes mais próximos ou exatos

\begin{tabular}{|c|c|}
\hline Grafemas & Correspondências fonológicas \\
\hline c, j & correspondem aos fonemas palatais $/ \mathrm{t} \int / \mathrm{e} / \mathrm{d} 3 /$, respectivamente. \\
\hline ğ & $\begin{array}{l}\text { corresponde ao fonema } / \eta / \text {, o qual em fim de sílaba, após vogal nasal, é } \\
\text { realizado como [n], e após vogal oral, [g]]; e, em início de sílaba, [n]. }\end{array}$ \\
\hline I & corresponde ao fonema oclusivo glotal / $/$. \\
\hline $\mathbf{m}$ & $\begin{array}{l}\text { corresponde ao fonema nasal } / \mathrm{m} / \text {, que após vogal oral é }[\mathrm{bm}] \text { em final de sílaba } \\
\text { e, nos demais ambientes, é }[\mathrm{m}] \text {. }\end{array}$ \\
\hline $\mathbf{n}$ & $\begin{array}{l}\text { corresponde ao fonema nasal } / n / \text {, que após vogal oral é [dn] em final de sílaba } \\
\text { e, nos demais ambientes, é [n]. }\end{array}$ \\
\hline $\mathbf{r}$ & corresponde ao fonema alveolar $/ \mathrm{r} /$ em qualquer ambiente. \\
\hline $\mathbf{w}, \mathbf{y}$ & correspondem aos fonemas assilábicos /w/ e /y/, respectivamente. \\
\hline $\mathbf{x}$ & corresponde ao fonema fricativo palatal $/ \mathrm{S} /$. \\
\hline $\mathbf{0}$ & corresponde ao fonema vocálico posterior alto $/ \mathrm{o} /$, que varia entre $[\mathrm{o}]$ e $[\mathrm{u}]$. \\
\hline $\mathbf{u}$ & corresponde ao fonema vocálico central médio /ə/. \\
\hline
\end{tabular}

\footnotetext{
${ }^{3}$ Uma etapa importante da pesquisa foi a definição das subáreas, as quais permitem que o conhecimento especializado seja transmitido e assimilado de maneira mais organizada, simples e eficiente, pois seu intuito é facilitar a compreensão dos termos dentro de um mesmo campo de atuação. Propomos para a área de Magistério seis subáreas. São elas: 1) Abordagens de Ensino-Aprendizagem (A.E.A.); 2) Corpo Escolar (C.E.); 3) Organização Escolar (O.E.); 4) Organização Pedagógica (O.P.); 5) Recursos Didáticos (R.D.) e 6) Lei (L.). (Cf. FERREIRA 2013).
} 
GOMES, D. M.; FerReIRA, T. B. - Equivalência e definição no Dicionário Bilíngue PortuguêsMundurukú da área do Magistério: contribuindo para a epistemologia terminológica e terminográfica

com relação a objetos que com relação a termos mais abstratos como os termos da subárea Abordagens de Ensino-Aprendizagem (A.E.A).

Mesmo nosso trabalho sendo de natureza terminológica, a equivalência única é rara em nossos dados. Apesar de existirem outros termos que apresentam apenas um equivalente, ele não expressa totalmente o mesmo valor semântico e conceitual, pois traz visões de mundo distintas, abarcando apenas parcialmente o conceito expresso no termo.

(2) alfabetizar i-mu-taybin bararak i-am

$\left\{3^{\text {a }}\right.$ pessoa-causativo-saber escrita -para $\}$

analfabeto $>$ i-taybit-ũm-at

$\left\{3^{\text {a }}\right.$ pessoa-saber-ausência-agentivo $\}$

O termo "alfabetizar" é morfológica e sintaticamente complexo em Mundurukú e revela o imaginário coletivo do povo sobre o processo de alfabetização. Nele, tem destaque o valor da aquisição da escrita, reflexo de sua aquisição recente e do papel que passou a ocupar na cultura Mundurukú. Essa ideia foi reforçada ao discutirmos o termo "analfabeto", pois ele também destaca o papel principal desempenhado pela escrita junto ao povo Mundurukú, que se refere ao analfabetismo com ênfase na falta de domínio da escrita; é uma relação metonímica, em que a falta desse domínio acaba por representar a falta de domínio do todo, ou seja, da escrita e da leitura.

(4) cabeçalho tõg̃pi-da-ap; tõg̃pi-da-da-ap

\{parte de trás e superior do corpo-verbalizador de nomesReduplicação-nominalizador de paciente\} 'literalmente, encabeçar.' 
Gomes, D. M.; FerReIRA, T. B. - Equivalência e definição no Dicionário Bilíngue PortuguêsMundurukú da área do Magistério: contribuindo para a epistemologia terminológica e terminográfica

O termo "cabeçalho" apresenta uma relação cultural interessante, pois é uma expressão utilizada quando o artesão vai iniciar seu trabalho; assim, temos um termo que saiu de uma área técnica para outra.

De acordo com CARVALHO (2001), a relação divergente entre equivalentes é comum entre duas línguas, mas não apresenta muita frequência. Essa relação expressa a existência de “(...) um lexema na línguafonte e vários na língua-alvo. Em outras palavras, não existe uma única equivalência plena, mas sim várias equivalências parciais, que juntas devem cobrir toda a extensão do lema" (CARVAlHo 2001: 114). Vejamos alguns exemplos oriundos de nosso dicionário: 
GOMES, D. M.; FeRREIRA, T. B. - Equivalência e definição no Dicionário Bilíngue PortuguêsMundurukú da área do Magistério: contribuindo para a epistemologia terminológica e terminográfica

Quadro 1 - Exemplo 1 de equivalência divergente entre Português e Mundurukú ${ }^{4}$

bullying jewemuwaramwaram/ isũsũn/dadaybotap;
imudadaybotap; jewemudadaybotap; $\quad$ gudadaybon;
imudadaybo s.m. A.E.A. violência física ou verbal que ocorre repetidamente
entre alunos ou entre professores e alunos, dentro e fora da escola, na forma de
brincadeiras que maltratam ou humilham. As crianças não devem zombar das outras
na sala de aula. Jenemurarammaram gu bit bekitkityũ je'edop etaybinbinap'a be. $\rightarrow$
ciberbullying.

Quadro 2 - Exemplo 2 de equivalência divergente entre Português e Mundurukú

cidadania ajebuyxiap; wuyjuyũyũ buyxiap; jewemubuyxi/
iebut imug̃ebutap s.f. A.E.A. Respeito aos valores da sociedade, aos direitos
e deveres das pessoas com igualdade e liberdade política e social. Seria bom para
todo mundo se nós nos respeitássemos. Soat wuyjuy xipat kuka o'e jewemubuyxixin
pima. É preciso ter mais respeito com os mais velhos. Ibuixin ajojoyũ ajukuk. < Nota:
Segundo ouvimos no trabalho de campo, o termo ajebuyxiap é usado com
alguém por quem se tem muito respeito, como um tipo de saudação; já wuyjuyüyũ
buyxiap se refere aos direitos, e iebut imug̃ebutap se refere aos deveres.> $\rightarrow$ cidadão;
direitos; deveres.

\footnotetext{
${ }^{4}$ Todos os quadros aqui expostos provêm de FerReIRA (2013) e constarão da versão final do Dicionário em construção pelos autores deste artigo. A cor azul nos equivalentes e exemplos indica a área do Magistério. Para as outras duas áreas do dicionário, serão usadas outras cores. Mantivemos aqui as fontes e tamanhos dos originais, trazendo o verbete como o concebemos. Os seguintes símbolos e abreviaturas foram usados nos quadros:

- usado para separar o termo em Português do termo em Mundurukú;

$<$ usados para conter a nota

$\rightarrow \quad$ usado para indicar remissão

/ usado para separar variantes lexicais distintas

; $\quad$ usado para separar variantes gramaticais (fonológicas, morfológicas, etc.)

A.E.A. Abordagem de Ensino-aprendizagem;

C.E. Corpo Escolar

O.E. Organização Escolar

O.P. Organização Pedagógica

R.D. Recursos Didáticos

Cf. Conferir

s. Substantivo

f. Feminino

m. Masculino
} 
Gomes, D. M.; FerReIRA, T. B. - Equivalência e definição no Dicionário Bilíngue PortuguêsMundurukú da área do Magistério: contribuindo para a epistemologia terminológica e terminográfica

Quadro 3 - Exemplo 3 de equivalência divergente entre Português e Mundurukú

letramento - ikõbida babi + kõbururuk + ibuetaybit/ibubabiat
+ a'õpisatap + a'õpibak + ag̃uybabiat + yag̃ũytok(tok)ap +
õbida babi + babi. s.m. A.E.A. conjunto de habilidades/saberes relacionados
com o domínio da fala, da escrita aprendidos principalmente na escola e que
permitem maior acesso aos bens sociais e culturais.<Nota: Vejamos o que
significa cada termo: ikõbida babi 'saber falar e ler' + kõbururuk 'falar difícil' +
ibuetaybit/ibubabiat 'habilidade de escrita'; 'artesão'; 'habilidade manual em
geral' + a'õpisatap 'compreensão da fala; usado para criança aprendendo a
entender' + a'õpibak 'começar a entender' + ag̃uybabiat 'interpretação'
+yag̃uytok(tok)ap 'criatividade' + õbida babi 'falar com facilidade e rapidez';
babi 'saber'. $\rightarrow$ alfabetizar, alfabetização, escrita, leitura, habilidades, saberes, fala, bem
social, bem cultural.

No primeiro quadro, encontramos, em Mundurukú, diversos termos que denominam atos que causam o bullying e por meio do exemplo essa relação é esclarecida. No segundo quadro, encontramos um termo que se refere a alguém respeitado, outro termo relacionado aos direitos e outro aos deveres, apresentando uma equivalência parcial e apenas a junção dos três abarca o conceito de "cidadania". Esse tipo de ocorrência recebe uma nota explicativa. Já o quadro 3 apresenta diversos termos que somados equivalem ao valor de letramento. Por haver uma grande quantidade de termos, fizemos uso do sinal (+), mostrando que é a soma dessas equivalências parciais que equivalem ao termo em Português. Essa entrada também apresenta uma nota explicativa.

Já a relação convergente entre equivalentes é a relação oposta à divergente, em que “(...) temos uma equivalência, que tem como correspondência mais de um lexema na língua-fonte" (CARVAlHo 2001: 115). Como essa relação é a oposta da divergente, podemos considerar os dados nos quadros 1, 2 e 3, porém na versão Mundurukú-Português.

A relação multivergente é “(...) uma combinação entre a convergência e a divergência, i.e., o lema possui mais de uma equivalência, as quais só 
Gomes, D. M.; FerReIRA, T. B. - Equivalência e definição no Dicionário Bilíngue PortuguêsMundurukú da área do Magistério: contribuindo para a epistemologia terminológica e terminográfica

cobrem parte dos significados do lema e podem, por sua vez, ter como correspondência outro(s) lema(s)" (CARVALHO 2001: 116). Em nossa pesquisa, não encontramos esse tipo de equivalência.

Por fim, existe ainda a possibilidade de ausência de equivalência:

Há, porém, um outro tipo de situação, em que o item só faz parte do universo real do falante da língua-fonte e, portanto, só possui expressão lexical nessa língua. Essa situação, associada a elementos culturais específicos de uma sociedade, não é tão incomum entre duas línguas e percorre os mais diversos campos semânticos, aparecendo, sobretudo, nas seguintes áreas: (a) atividades e festividades, (b) vestuário, (c) utensílios, (d) fatos históricos, (e) comidas e bebidas, (f) religião, (g) educação e áreas especializadas. (SCHORR 1986: 56-60 apud CARVALHO 2001: 117)

Muitos termos do Português não tinham equivalentes ainda pensados e correntes em Mundurukú. É o caso de letramento (quadro 3). Nesse caso, a equivalência foi construída em uma oficina terminológica, da qual fez parte professores mundurukú e outros participantes igualmente falantes plenos dessa língua. Desse modo, os neologismos estão fortemente presentes em nosso dicionário. Passemos a discutir a construção das definições.

\section{Definições}

A elaboração de uma definição para um verbete é um trabalho bastante complexo, sobretudo quando nos atentamos para o nível de letramento em que se encontra o nosso público-alvo, alunos do ensino médio Mundurukú. Em um primeiro momento, recorremos aos dicionários especializados da área da Educação, com o objetivo de analisar a forma como os termos eram tratados e aprofundar o conhecimento sobre cada termo. Registramos, em uma ficha terminológica, no mínimo duas definições do termo apresentadas prioritariamente em dicionários especializados; porém, foi necessário fazer 
Gomes, D. M.; FERREIRA, T. B. - Equivalência e definição no Dicionário Bilíngue PortuguêsMundurukú da área do Magistério: contribuindo para a epistemologia terminológica e terminográfica

uso de dicionários de língua geral e material/texto especializado que já trazia uma definição sobre o termo de que tratávamos. Isso se deu porque i) não há uma grande variedade de dicionários que abordem os termos da área do Magistério/Educação; ii) não são obras com uma quantidade exaustiva de termos, pois alguns se restringiam à determinada subárea da Educação; e iii) principalmente, por questões relacionadas à má qualidade propriamente das obras disponíveis.

Após o estudo dos termos coletados e a busca de definições em dicionários com o intuito de compreender melhor o termo e analisar formas de abordá-lo, defini-lo e adaptar ao nosso público-alvo, é que se iniciou o trabalho de elaboração de uma proposta de definição nossa.

A primeira dificuldade encontrada está relacionada à linguagem utilizada. Apesar de nosso dicionário ser um dicionário terminológico, não poderíamos simplesmente usar uma linguagem muito técnica. Daí o desafio: como conciliar o valor técnico com o caráter escolar de nossa obra? Esse caráter escolar, portanto, exigia uma linguagem mais simples e didática para atrair e facilitar o entendimento dos alunos.

Além de ser terminológico e escolar, nosso dicionário é bilíngue, o que gera mais uma série de questões referentes à linguagem, pois temos como público-alvo os alunos do ensino médio Mundurukú, os quais apresentam diferentes graus de bilinguismo, fazendo com que o domínio do Português e do Mundurukú seja variado. Outro fator que influencia na falta de domínio pleno das línguas, sobretudo da escrita, é que os indígenas enfrentam inúmeras dificuldades relacionadas à garantia de um ensino de qualidade; por isso, os alunos encontram-se em um nível de letramento bem abaixo do esperado para o ensino médio.

Todas essas questões refletem-se diretamente na forma como a definição deve ser apresentada no dicionário. Por isso, buscamos tornar a definição mais objetiva, clara e simples possível, com uma linguagem 
GOMES, D. M.; FerReIRA, T. B. - Equivalência e definição no Dicionário Bilíngue PortuguêsMundurukú da área do Magistério: contribuindo para a epistemologia terminológica e terminográfica

acessível ao nosso público-alvo, sem perder o seu valor técnico. Vejamos alguns casos e reflexões relacionadas à construção das definições:

Quadro 4 - Exemplo 1 de definição

bullying jewemuwaramwaram/ isũsũn/dadaybotap;
imudadaybotap; jewemudadaybotap; gudadaybon;
imudadaybo s.m. A.E.A. violência física ou verbal que ocorre repetidamente
entre alunos ou entre professores e alunos, dentro e fora da escola, na forma de
brincadeiras que maltratam ou humilham. As crianças não devem zombar das outras
na sala de aula. Jewemuvaramvaram g̃u bit bekitkityú je'edop etaybinbinap'a be. $\rightarrow$
ciberbullying.

$\mathrm{Na}$ definição presente no quadro 4, o primeiro aspecto sobre o qual refletimos foi a questão do uso de "entre" repetidamente, pois isso poderia tornar a definição mais pesada e dificultar o entendimento do nosso públicoalvo; porém, ao ser testado nas oficinas terminológicas, esse uso não dificultou o entendimento dos alunos indígenas. Também optamos pelo uso de "ocorre" e não "ocorra" conscientemente, pensando no maior domínio que os estudantes têm do indicativo frente ao subjuntivo.

Quadro 5 - Exemplo 2 de definiçãa

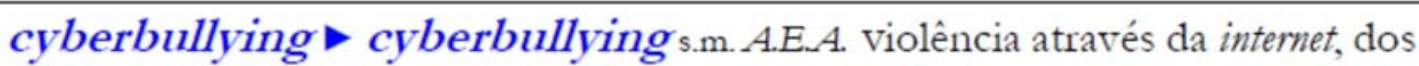
celulares, das câmeras fotográficas ou qualquer outro meio eletrônico que ocorre no dia a dia entre alunos ou entre professores e alunos, dentro e fora da escola, na forma de brincadeiras que maltratam ou humilham. $\rightarrow$ bullying, internet.

$\mathrm{Na}$ definição de cyberbullying, além dos aspectos já citados no exemplo de bullying, o uso do "através" foi escolhido por deixar o texto mais acessível, e o uso do "da" e não do "de" para deixar a linguagem mais clara, facilitando assim o entendimento e aproximando a definição da variedade do Português com que os Mundurukú têm maior contato. 
Gomes, D. M.; FERREIRA, T. B. - Equivalência e definição no Dicionário Bilíngue PortuguêsMundurukú da área do Magistério: contribuindo para a epistemologia terminológica e terminográfica

Quadro 6 - Exemplo 3 de definição

cidadão ajebuyxi ; imubuyxin s.m. C.E. Pessoa que respeita outras pessoas e também é respeitada, exercendo livremente seus direitos e cumprindo seus deveres. $\rightarrow$ cidadania, direito, dever.

Com esse exemplo presente no quadro 6, podemos ver que evitamos omissões previsíveis (a palavra "pessoas"), pois elas são previsíveis para falantes nativos de Português; optamos, então, pela explicitação total, mesmo com repetição, para atingir o máximo de compreensão do aluno Mundurukú.

Outra dificuldade encontrada foi quando, ao definir um termo, precisamos fazer uso de outro termo, como no exemplo abaixo:

Quadro 7 - Exemplo 4 de definição

escola \ etaybinbinap'a/ imutaybinbinap'a /mutaybin ap'a/ eskora'a s.f. O.E. Lugar onde se ensinam muitas pessoas para formar cidadãos e desenvolver suas habilidades e conhecimentos. Eu estou trabalbando na escola. Imutaybinbinap'a be õn kapikpig. $\rightarrow$ cidadão, conhecimento, habilidade.

Optamos por deixar os termos "habilidades" e "conhecimentos" na definição e não buscar outra forma de simplificá-la porque, como são termos da área que o aluno deverá dominar (Magistério), resolvemos mantê-los para ampliar seu contato com as terminologias; obviamente, fazemos uso de remissão para esses termos com o intuito de completar a compreensão.

Destacamos que todas as definições foram previamente testadas e discutidas com colaboradores indígenas nas oficinas terminológicas, fazendo com que as dúvidas fossem esclarecidas.

Tendo conhecimento da relação diglóssica vivida pelos mundurukú, é preciso observar e analisar os espaços de uso de cada língua em um contexto bilíngue com o objetivo de demonstrar a riqueza da língua indígena, que, muitas vezes, é tida erroneamente como inferior. Por isso, a necessidade de 
Gomes, D. M.; FerReIRA, T. B. - Equivalência e definição no Dicionário Bilíngue PortuguêsMundurukú da área do Magistério: contribuindo para a epistemologia terminológica e terminográfica

projetos que adotem a postura de um bilinguismo funcional e pluralista (GOMES 2010), a fim de reconhecer o status da língua dominada para ela chegar às funções de poder e futuramente atingir, quem sabe, um ideal de planificação linguística.

Para que nosso dicionário possa realmente dar o mesmo espaço para as duas línguas, é preciso levar em consideração as interações sociais e usos dessa terminologia em seus contextos. Para isso, é preciso entender quem é o sujeito e como ele foi construído de acordo com suas experiências, historicidade e inserção em sua cultura. Analisando os dados por meio dessa perspectiva, é possível perceber o quanto é complexo e enriquecedor trabalhar com culturas distintas, pois percebemos o quanto podemos aprender com esse saber diferente do nosso. Torna-se possível, assim, desconstruir discursos enraizados em nossa sociedade que avaliam uma cultura e uma língua como inferior a outra, compreendendo que isso não passa de um grande erro, que envolve questões ideológicas e de poder.

O povo Mundurukú em seus discursos inclui sempre o sujeito como um participante ativo do processo, pois em sua cultura não existe essa impessoalidade das relações e isso também se reflete na forma como as terminologias são recebidas e assimiladas no seu contexto escolar. E é justamente essa subjetividade apresentada nas terminologias em Mundurukú que as aproximam das concepções ideais de Educação mais valorizadas hoje.

Com o objetivo de verificar as marcas de subjetividade, analisaremos alguns termos em Português e seus equivalentes em Mundurukú. Foram selecionados termos cujas definições eram possíveis de se encontrar em dicionários de termos da área.

O termo "aluno" tem como definição: "Quem recebe instrução de um ou mais professores em um estabelecimento de ensino ou privativamente. Pessoa matriculada em estabelecimento de ensino. Estudante. Educando. Discípulo. Escolar" (DUARTE 1986:10). É possível perceber, por meio dessa definição, que o aluno é um paciente, sofre a ação de outra pessoa, sendo a 
Gomes, D. M.; FERREIRA, T. B. - Equivalência e definição no Dicionário Bilíngue PortuguêsMundurukú da área do Magistério: contribuindo para a epistemologia terminológica e terminográfica

outra pessoa agente. Apesar das novas teorias pedagógicas buscarem mudar essa concepção de aluno, ela ainda está enraizada na nossa cultura.

Em Mundurukú, para aluno temos:

(5) aluno

- etaybin-bin-at

\{aprender-reduplicação-nominalizador de agente\}.

Literalmente, 'aquele que tem o hábito de aprender. '

Partindo da estrutura morfológica presente no termo etaybinbinat, já é possível perceber uma visão diferente em relação à visão de mundo transmitida pelo termo no dicionário de Português, pois em Mundurukú o aluno é um ser que age; ele é agente no processo de aprendizagem e não paciente graças ao nominalizador de agente $\{$-at $\}$. Outro fator importante é a reduplicação no termo em Mundurukú, que enfatiza o valor processual do verbo "aprender". Desse modo, a proposta de definição estabelecida foi:

Quadro 8 - Exemplo 5 de definição

aluno; alunos - etaybinbinat; etaybinbinayũ s.m. C.E. Pessoa matriculada em uma escola, universidade, curso para aprender e construir novos conhecimentos. Os alunos voltaram para sua casa. Etaybinbinaỹu o'jepitjeduk 'a be. Os alunos estão brincando. Etaybinbinaỹu pubutbun. $\rightarrow$ conhecimento, aprender.

Enfatizamos, na definição, a relação com o "aprender" e a construção do conhecimento, pois dentro dessa concepção o aluno é agente do processo de ensino-aprendizagem, constrói o conhecimento e não só o absorve. Assim, buscamos respeitar a visão de mundo Mundurukú e incentivamos as atuais tendências da Educação Escolar em nossa sociedade.

Com o termo "aprender", também é possível identificar essa relação. Em Português, ele tem a seguinte definição: “Adquirir conhecimento. Fixar 
GOMES, D. M.; FeRreIRA, T. B. - Equivalência e definição no Dicionário Bilíngue PortuguêsMundurukú da área do Magistério: contribuindo para a epistemologia terminológica e terminográfica

na memória o que foi ensinado. Instruir-se." (DUARTE 1986:14). Em Português, este é um verbo que, dependendo do contexto, o indivíduo que aprende está envolvido no processo de forma ativa, mas também é possível que ele seja passivo.

Em Mundurukú, o termo equivalente é "jewemutaybin", e sua divisão morfológica é a seguinte:

(6) aprender

- je-we-mu-taybin

\{voz média-reflexivo-causativo-verbo aprender\}. Literalmente, 'fazer alguém saber algo por si mesmo e em si mesmo.'

Em Mundurukú, o sujeito faz parte do processo e está envolvido nele, o que é indicado pela voz média e o reflexivo. Em Mundurukú, mesmo quando o aluno é paciente, é ele que se deixa ser, uma vez que o aprendizado é construído quando o sujeito o descobre por si mesmo e em si mesmo (voz média).

Outro termo importante para observar é "avaliação" que em Português. Em nossa pesquisa, descobrimos que o termo "avaliação" em nossa sociedade apresenta duas acepções. Uma está difundida em nossa cultura porque foi utilizada durante séculos nas tendências liberais. Com essa visão, a "avaliação" relaciona-se com aprovação e reprovação, um ganhador e/ou um perdedor, além de servir como meio disciplinador por meio de ameaças, sendo utilizada para medir a capacidade dos alunos de forma quantitativa. Nessa acepção, o professor tem papel de destaque porque ele classifica os alunos de acordo com sua apreciação.

A outra acepção de "avaliação" relaciona-se com as tendências progressistas e somente nas últimas décadas do século XX passou a ser discutida. Essa é a visão de "avaliação" almejada atualmente. Porém, encontram-se dificuldades para aplicá-la, pois a outra visão já está enraizada 
GOMES, D. M.; FeRREIRA, T. B. - Equivalência e definição no Dicionário Bilíngue PortuguêsMundurukú da área do Magistério: contribuindo para a epistemologia terminológica e terminográfica

em nossa cultura e, mesmo com os espaços para difundi-la nos atuais programas do governo, existem dificuldades ao colocá-la em prática, uma vez que o governo faz uso de mecanismos quantitativos para avaliar os sistemas de ensino. Esta visão apresenta a "avaliação" como um processo, em que o professor faz uma avaliação preliminar, reconhecendo o conhecimento que o aluno sabe para, com base nesses dados, fazer o planejamento de suas ações com o objetivo de desenvolver as habilidades de seus alunos para uma melhor aprendizagem (GOMES \& FERREIRA 2012).

O termo "avaliação" em Mundurukú tem a seguinte estrutura morfológica:

(7) avaliação paciente\}
- i-buyxijo-ap

$\left\{3^{\text {a }}\right.$ pessoa-verbo desafiar/enfrentar-nominalizador de

Com base nesses morfemas, verificamos que o verbo tem a seguinte valência semântica: [X-agente desafia $Y$-paciente], sendo um verbo transitivo em termos de sua valência sintática. 0 morfema $\{-a\}$ indica um caráter semântico de paciente para a avaliação, enquanto o agente desafiante é o aluno; assim a avaliação é que é a desafiada; por sua vez, o aluno é [+ agente, + controle, + instigador, + desencadeador do processo] e não o contrário como ocorre com a nossa "avaliação" tradicional (GOMES \& FerReIRA 2012). Nossa proposta de definição é: 
GOMES, D. M.; FerReIRA, T. B. - Equivalência e definição no Dicionário Bilíngue PortuguêsMundurukú da área do Magistério: contribuindo para a epistemologia terminológica e terminográfica

Quadro 9 - Exemplo 6 de definição

avaliação $\bullet$ ibuixijoap s.f. O.P. 1. Processo de acompanhamento/medição do desenvolvimento dos alunos no seu dia-a-dia, dentro e fora da escola, para que o professor possa planejar melhor as suas ações. 2. Desafio a ser vencido. Eu desafiei o Amâncio. õn Amâncio osubuixijo. Hoje tem prova. g̃asũ kake ibuixijoap. Hoje tem prova de bistória gasũ kake ibuixijoap bistoria iap. Eu testei a matemática. òn matematika osubuixijo. < Nota: Entre os Mundurukú, o conceito de avaliação é associado com o conceito de desafio. $>\rightarrow$ prova; desafio; teste; experimento.

A primeira acepção refere-se ao que representa "avaliação" em nossa sociedade. A segunda acepção representa a visão de mundo do povo Mundurukú em relação à "avaliação". Assim, demos espaços para os dois modos de concebê-la.

Já o termo "educador" em Português é definido:

O que educa. Pedagogo. Pessoa que intencionalmente exerce influência duradoura sobre o desenvolvimento cognitivo, afetivo e psicomotor de outra, ou a ajuda em seu processo global de desenvolvimento. 0 professor não é necessariamente educador; este, por seu turno, não é necessariamente professor, ou pessoa culta ou letrada. (DUARTE 1986: 61)

Partindo da definição mais ampla de "educador", nos torna possível inferir que o sujeito que é educado é paciente no processo; portanto, quem ou o que educa é agente.

O termo em Mundurukú tem a seguinte estrutura morfológica:

(8) educador i-mu-ã̃ũysan-'uk-at

$\left\{3^{\text {a }}\right.$ pessoa-causativo-pensamento-habitual-nominalizador.de.agente\}

Literalmente, 'aquele que tem o hábito de fazer amadurecer o pensamento de alguém.' 
Gomes, D. M.; FERREIRA, T. B. - Equivalência e definição no Dicionário Bilíngue PortuguêsMundurukú da área do Magistério: contribuindo para a epistemologia terminológica e terminográfica

Aqui, podemos perceber que, em Mundurukú, educador também é agente, mas a presença do morfema causativo, implica que o aluno também é agente no processo de aprendizagem. A proposta de definição foi:

Quadro 10 - Exemplo 7 de definição

educador \ imuag̃ũysan'ukat s.m. C.E. Pessoa que nos ajuda a construir o conhecimento, despertando a curiosidade, desenvolvendo a autonomia, o senso crítico dos estudantes, em busca do sucesso da sua formação escolar, humana e social. Falta um educador na escola. Imuag̃üusan'ukat ma omuyku etaybinbinap'a be. <Nota: Em Mundurukú, significa ao pé da letra "aquele que faz amadurecer o pensamento". $>\rightarrow$ autonomia, senso crítico, professor.

Com essa definição, buscamos enfatizar o processo de construção do conhecimento em que o "educador" é um facilitador do processo e não o único agente, uma vez que o aluno é quem constrói o aprendizado.

Outro aspecto relevante ao abordar a forma como propomos as definições para nosso dicionário diz respeito ao fato de que alguns termos, sobretudo da subárea "Recursos Didáticos (RD)", por estarem amplamente difundidos no léxico comum do Português, geralmente não são explorados como terminologias. Porém, como nosso público-alvo não é o falante do Português como língua materna e por valorizarmos os aspectos didáticos que tais recursos possam ter, incluímos tais termos no dicionário e utilizamos da definição para enfatizar o seu valor terminológico. Vejamos alguns exemplos:

Quadro 11 - Exemplo 8 de definição

cartaz/ cartolina $>$ taperadup xixidup s.m. R.D. Trabalho escolar com imagens e informações que é usado por alunos e professores para apresentar um certo assunto. A escolha de um carta\% \ taperadup xixidup taẽap. Pegue a cartolina. - taperadup xixidup etuppu. Está escrito no cartaz - Taperadup xixidup pararak pe opop./ taperadup xixidup pe opop ibararak. Fagam o carta\% D Taperadup xixidup barabak pe epeg̃ẽ g̃êm./ taperadup xixidup epetup mũgẽ. $\rightarrow$ trabalho escolar; ilustrado. 
GOMES, D. M.; FerReIRA, T. B. - Equivalência e definição no Dicionário Bilíngue PortuguêsMundurukú da área do Magistério: contribuindo para a epistemologia terminológica e terminográfica

Quadro 12 - Exemplo 9 de definição

impressora - impresora s.f. R.D. Máquina capaz de passar os dados de um computador para o papel, sendo útil na elaboração de atividades escolares para os estudantes e documentação da escola. $\rightarrow$ computador, papel, atividades, documentação da escola.

Quadro 13 - Exemplo 10 de definição

mesa jekõnkõnap/ meza s.f. R.D. Móvel com superfície plana e horizontal apoiada geralmente sobre quatro pernas, e utilizado na escola principalmente como apoio de livro, caderno, computador, projetor. <Nota: jekõnkõnap 'mesa onde se come'. $>\rightarrow$ livro, caderno, computador, projetor.

Com esses exemplos, é possível perceber que nossas acepções se preocupam em dar mostras de que o item lexical de entrada tem um valor terminológico, um valor especializado. Vale ressaltar que, no caso de “cartaz", e para alguns itens, é mais viável defini-los pelo objetivo e não pelo que são propriamente. Por isso, destacamos que o trabalho em forma de “cartaz" tem duas funções específicas: informativa e ilustrativa.

O trabalho de propor uma definição foi bastante complexo. As oficinas terminológicas permitiram que a participação dos indígenas fosse fundamental no trabalho e viabilizasse meios de simplificá-las, de abrir espaço para abordar a visão de mundo deles e facilitar o acesso do nosso público-alvo.

\section{Considerações finais}

Neste artigo, trouxemos ao debate os desafios que nos colocam as línguas indígenas brasileiras, sobretudo no tocante à produção de uma obra terminográfica escolar. Há termos em línguas indígenas? A resposta implícita 
Gomes, D. M.; FERREIRA, T. B. - Equivalência e definição no Dicionário Bilíngue PortuguêsMundurukú da área do Magistério: contribuindo para a epistemologia terminológica e terminográfica

em nosso trabalho é sim. A necessidade de especializar itens lexicais para dadas áreas do conhecimento é inerente à qualquer língua. Todo e qualquer povo tem Ciência ao lidar com conhecimentos especializados, individualizados.

Então, é possível encontrar equivalentes de termos do Português (da área do Magistério) em Mundurukú? A essa pergunta também se responde sim aqui, mostrando-se toda complexidade que existe nessa interação entre línguas, ou melhor, entre povos de línguas tão diferentes, reflexo de perspectivas socioculturais tão distintas. A diversidade de tipos de equivalência na relação Português-Mundurukú evidencia o quanto se deve ter cuidado na elaboração de obras bilíngues.

Por seu turno, as definições presentes no Dicionário Terminológico Escolar Português-Mundurukú: Magistério que foram aqui discutidas também mostram, ao campo da Terminologia/Terminografia, necessidades de primeira ordem: o reconhecimento da visão de mundo de cada povo, a qual deve ser considerada necessária e responsavelmente na construção das definições de termos. 0 desafio é dobrado, uma vez que o caráter bilíngue exige que a definição dê conta dos dois povos representados pelas duas línguas.

Nesse sentido, citamos a necessidade de uma Terminologia Cultural, nos termos de DIKI-KIDIRI (2009), ou melhor de uma Etnoterminologia (BARBOSA 2006, 2009; COSTA \& GOMES 2011, 2013a, 2013b). DIKI-KIDIRI (2009: 2) argumenta que "el hombre no puede acceder a este mundo real nada más que a través de las representaciones mentales y culturalmente condicionadas. La representación de la realidad se hace, a menudo, de forma muy distinta de una cultura a otra (...)". Nesse sentido, temos de buscar as leituras culturais presentes nos termos encontrados, reconhecer o valor da cultura na construção das definições e nas equivalências.

Ainda sobre uma Etnoterminologia, como pontuam COSTA \& GOMES (2013b: 2), 
GOMES, D. M.; FeRreIRA, T. B. - Equivalência e definição no Dicionário Bilíngue PortuguêsMundurukú da área do Magistério: contribuindo para a epistemologia terminológica e terminográfica

No Brasil, BARBOSA (2004, 2006, 2009) propõe o emprego do termo "etnoterminlogia" para definir a área que "estuda os discursos etnoliterários, como os de literatura oral, literatura popular, literatura de cordel, fábulas, lendas, mitos, folclore e os discursos das linguagens especiais com baixo grau de tecnicidade e de cientificidade" (BARBOSA, 2009, p. 1). Barbosa procura traçar um método e uma definição para a área. Porém, a sua etnoterminologia não abrange o nosso objeto de estudo e método de pesquisa.

Nosso presente trabalho é tributário dos trabalhos de Costa \& Gomes e se vale do mesmo conceito de Etnoterminologia desses autores e de semelhante método de pesquisa. Nossas pesquisas têm gerado uma Etnoterminologia própria, diferente da de BARBOSA (2004, 2006, 2009). COSTA \& Gomes (2011, 2013a, 2013b), por exemplo, argumentam a favor de uma Terminologia que aborde as questões Etnográficas. Nós podemos também lançar mão do termo "Etnoterminologia" para

(...) definir uma terminologia voltada para os conhecimentos técnicos e científicos de uma determinada comunidade indígena, quilombola, ribeirinha ou tradicional que possua conhecimentos e práticas tradicionais associadas à sua subsistência, de ordem sanitária, alimentar e/ou cultural. Há, portanto, uma diferença quanto ao objeto de estudo principal entre os dois empregos conhecidos do termo "Etnoterminologia" no Brasil, posto que Barbosa foca-se especialmente nos discursos etnoliterários e considera os termos desses discursos possuidores de "(...) baixo grau de tecnicidade e de cientificidade" (BARBOSA 2009: 1). (COSTA \& GOMES 2013b: 2)

Já nós focamos nos discursos dos professores Mundurukú, uma etnia indígena brasileira, e os consideramos possuidores de alto grau de tecnicidade e cientificidade, ampliando o conceito de técnica e ciência, que não ficará mais restrito ao praticado nos paradigmas ocidentais. 
Gomes, D. M.; FERREIRA, T. B. - Equivalência e definição no Dicionário Bilíngue PortuguêsMundurukú da área do Magistério: contribuindo para a epistemologia terminológica e terminográfica

Este trabalho é apenas parte de uma discussão muito maior, que envolve ainda variação, ortografia, contrastes morfológicos e o tratamento de empréstimos nesse fértil campo da Terminologia/Terminografia com línguas indígenas brasileiras em contato com o Português. Sobre esses temas, outros artigos estão em preparação. Por ora, esperamos ter contribuído, humildemente, para a epistemologia terminológica e terminográfica bilíngue a partir de línguas indígenas, refletindo sobre desafios encontrados em questões referentes a equivalências e definições, e propondo soluções para um dicionário terminológico escolar bilíngue.

\section{Referências Bibliografias}

Barbosa, M. A. Para uma etno-terminologia: recortes epistemológicos. Cienc. Cult. [online]. V. 58, n. 2. 2006, pp. 48-51.

BARBOSA, M. A. Cultura popular amazônica em etno-terminologia. Anais da $61^{\underline{a}}$ Reunião Anual da SBPC - Manaus, AM - Julho/2009.

CABRÉ, M. T. Elementos para uma teoría de la terminologia: hacia un paradigma alternativo. Lenguara, Buenos Aires, v. 1, n. 1. 1998, pp. 59-78.

CABRÉ, M. T. La terminología: representación y comunicación. Barcelona: Universitat Pompeu Fabra, 1999.

CABRÉ, M. T. Theories of Terminology: their description, prescription and explanation. Terminology, v. 9, n. 2. 2003, pp. 163-200.

CABRÉ, M. T. La Terminología, una disciplina en evolución: pasado, presente y algunos elementos de futuro. Debate Terminológico, 2005. Disponível em: <http://seer.ufrgs.br/riterm/article/view/21286/12263> (12/01/2013).

CARVALHO, O. L. de S. Lexicografia bilíngüe português/alemão: teoria e aplicação à categoria das preposições. Brasília: Thesaurus, 2001.

CostA, N. M. P. \& Gomes, D. M. (Etno)terminologia na (etno)medicina Mundurukú. Anais do VII Congresso Internacional da Abralin, 2011: 3412-3423. 
GOMES, D. M.; FerReIRA, T. B. - Equivalência e definição no Dicionário Bilíngue PortuguêsMundurukú da área do Magistério: contribuindo para a epistemologia terminológica e terminográfica

COSTA, N. M. P. ; GOMES, D. M. A etnoterminologia da língua Mundurukú (Tupí) e as contribuições da Ecolinguística. Cadernos de Linguagem e Sociedade, v. 14, 2013a, pp. 252-274.

COSTA, N.M.P.; GOMES, D. M. Etnoterminologia do sistema tradicional de cura e cuidado Mundurukú: introdução a princípios epistemológicos e práticos. In: Marília FerReIRA. (Org.). Tradições orais: mantendo vivas as vozes da floresta. 1ed.São Paulo: Pontes, 2013b, pp. 1-14.

DIKI-KIDIRI, M. Un enfoque cultural de la terminología. Debate Terminológico, No. 5, Ago. 2009.

DUARTE, S. G. Dicionário brasileiro de educação. Rio de Janeiro: Edições Antares: Nobel, 1986.

FAULSTICH, E. Socioterminologia: mais que um método de pesquisa, uma disciplina. Ciência da Informação, (S.l.), v. 24, n. 3, 1995 - artigos. Disponível em:<http://revista.ibict.br/index.php/ciinf/article/view/486/441> $(11 / 11 / 2012)$.

FAULSTICH, E. Socioterminologia, mais que um método de pesquisa, uma disciplina. Ciência da Informação. Brasília, v. 24, n. 3. 1996, pp. 281-288.

FERREIRA, T. B. Terminologia em língua indígena: a construção do dicionário escolar Português-Mundurukú na área do Magistério. Dissertação (Mestrado em Linguística) - PPGL, Universidade de Brasília, Brasília. 2013. $141 \mathrm{f}$.

GaUDIN, F. Socioterminologie: des problèmes semantiques aux pratiques institutionnelles. Rouen: Publications de l'Université de Rouen, 1993.

Gomes, D. M. Estudo morfológico e sintático da língua Mundurukú (Tupí). Tese (Doutorado em Linguística) - PPGL, Universidade de Brasília, Brasília. 2006: $299 f$.

GOMES, D. M. Por uma educação bilíngue pluralista e funcional: os espaços do mundurukú (tupí) e do português no âmbito da terminologia escolar indígena. In: Libro de Actas II Encuentro de Lenguas Indígenas Americanas y II Simposio Internacional de Lingüística Amerindia Asociación de Lingüística y Filología de América Latina (ALFAL). Resistencia (Argentina): CONICET, 2010.

GOMES, D. M.; FerReIRA, T. B. "Avaliação escolar”: termo, conceito e visão de mundo em português e em Mundurukú (Tupí). In: Cadernos de Linguagem e Sociedade. Vol. 13, nº 1, Brasília: Thesaurus/NELiS/CEAM/UnB, 2012: 56-81. 
GOMES, D. M.; FerReIRA, T. B. - Equivalência e definição no Dicionário Bilíngue PortuguêsMundurukú da área do Magistério: contribuindo para a epistemologia terminológica e terminográfica

KRIEGer, M. da G. Terminologia revisitada. In: KRIEGer, M. da G.; MACIEL, A.M.B. (Orgs.). Temas de Terminologia. Porto Alegre/São Paulo: Universidade/UFRGS/Humanitas/USP, 2001, pp. 47- 60.

KRIEGER, M. da G; FinatTo, M. J. B. Introdução à terminologia: teoria e prática. São Paulo: Contexto, 2004.

Ramos, A. Ensino Médio Integrado à Educação Profissional Técnica de Nível Médio para Habilitação de Técnico em Agrofloresta, Enfermagem ou Magistério: projeto Munduruku. 2006. 